\title{
The cellular signature of urinary immune cells in Lupus nephritis: new insights into potential biomarkers
}

Katharina Kopetschke ${ }^{1 \dagger}$, Jan Klocke ${ }^{1 \dagger}$, Anna-Sophie Grießbach ${ }^{1}$, Jens Y Humrich ${ }^{1}$, Robert Biesen ${ }^{1}$, Duska Dragun ${ }^{2}$, Gerd-Rüdiger Burmester ${ }^{1}$, Philipp Enghard ${ }^{1,2^{*}+}$ and Gabriela Riemekasten ${ }^{1,2+}$

\begin{abstract}
Introduction: Urinary T cells represent a reliable noninvasive biomarker for proliferative Lupus nephritis (LN). Little is known about the presence of T cell subsets, B cells and macrophages in the urine although they may further improve the validity of urinary cellular biomarkers for LN.

Methods: We analyzed contemporaneous blood and urine samples of patients with active LN $(n=19)$, other Systemic Lupus Erythematosus (SLE) patients $(n=79)$ and urine samples of patients with diabetic nephropathy ( $D N ; n=14$ ) and anti-neutrophil cytoplasmatic antibody (ANCA) associated vasculitis (AAV; $n=11$ ) by flow cytometry.

Results: Numbers of urinary T cells, B cells and macrophages correlated with disease activity and were significantly higher in the active LN group. Urinary T cells showed excellent distinction of patients with active LN, CD8+ T cells (AUC of ROC $=1.000)$ and $C D 4+T$ cells (AUC $=0.9969)$ alike. $C D 19+B$ cells $(A \cup C=0.7823)$ and $C D 14+$ macrophages $(A \cup C=$ 0.9066), as well as the clinical standard proteinuria (AUC $=0.9201$ ), failed to reach these high standards. Patients with DN or AAV also showed increased urinary cell counts, although the CD4/CD8-ratio was significantly lower in SLE compared to in DN $(p=0.0006)$. Urinary CD4+ T cells of active $L N$ patients proved to be mainly of effector memory phenotype and expressed significantly more CD40L and ki67 than corresponding blood cells. Urinary Treg counts correlated with disease activity.
\end{abstract}

Conclusions: Despite of detectable urinary cell counts for B cells and macrophages, T cells remain the best urinary cellular biomarker for LN. A low CD4/CD8-ratio seems to be characteristic for LN.

\section{Introduction}

Lupus nephritis (LN) is one of the most common manifestations of systemic lupus erythematosus (SLE) [1]. Although therapy has improved over the years, LN is still one of the most threatening complications implying the hazard of terminal renal failure and increased mortality [2]. Current care of patients with LN may further be improved by establishing new biomarkers for diagnosis and treatment monitoring, facilitating early diagnosis and helping avoid over- and under-treatment [3,4].

\footnotetext{
* Correspondence: Philipp.Enghard@Charite.de

${ }^{\dagger}$ Equal contributors

'Department of Rheumatology and Clinical Immunology, Charité Universitätsmedizin Berlin, Berlin, Germany

${ }^{2}$ Department of Rheumatology, Universitätsklinikum Schleswig-Holstein, Lübeck, Germany
}

\section{Biomed Central}

(c) 2015 Kopetschke et al.; licensee BioMed Central. This is an Open Access article distributed under the terms of the Creative Commons Attribution License (http://creativecommons.org/licenses/by/4.0), which permits unrestricted use, distribution, and reproduction in any medium, provided the original work is properly cited. The Creative Commons Public Domain Dedication waiver (http://creativecommons.org/publicdomain/zero/1.0/) applies to the data made available in this article, unless otherwise stated.
Kidney biopsy is usually applied to diagnose LN in SLE patients with a combination of systemic disease activity and abnormally elevated urinary markers, such as proteinuria [5]. The potential inaccuracy of the established urinary markers and the risk of invasive biopsy [6] led to the search for alternative biomarkers. Although both serum and urine have been examined for viable markers, urinary compounds are generally considered to show a better reflection of renal inflammation and irreversible kidney damage [7-9].

In a recent study we were able to show that urine samples of patients with acute proliferative LN contain high amounts of $\mathrm{CD} 3+\mathrm{CD} 4+\mathrm{T}$ cells which can be assessed by flow cytometric analysis [10]. The $\mathrm{T}$ cell count can be used as a biomarker for proliferative LN among SLE patients $[10,11]$. The urinary cells are also a phenotypical correlate of the kidney's interstitial infiltration [12,13], 
which is a common element of LN and correlates closely with disease activity and kidney damage [14-16]. This resemblance leads to the assumption that the urinary cells originate from the inflamed kidney rather than peripheral blood. Cells in the infiltrate are comprised mainly of $\mathrm{T}$ cells but also of macrophages, $\mathrm{B}$ cells and plasma cells [16-18]. Based on our hypothesis, other cell types besides $\mathrm{CD} 3+\mathrm{CD} 4+\mathrm{T}$ cells should also be detectable in the urine of LN patients and may be used as biomarkers.

The urine - and urinary cells in particular - can possibly be used to noninvasively explore the cellular components of the inflammatory renal environment. In addition, assessment of urinary cells may yield predictive markers for the patients' outcome, therapy response or future nephritis flares. We and others previously demonstrated that urinary $\mathrm{T}$ cells are also found in other nephropathies with inflammatory infiltration, such as diabetic nephropathy (DN) or anti-neutrophil cytoplasmatic antibody (ANCA)associated vasculitis (AAV) $[10,19]$. As yet there is no evidence on whether there are any differences between diseases in the occurrence or composition of urinary cells.

In the present study we analyzed the urinary cellular profile of patients with SLE, DN and AAV for T cells and their subsets, B cells and macrophages in order to obrain a thorough view of urinary cells in SLE, and further refine their diagnostic value as biomarkers for LN.

\section{Methods}

\section{Ethics approval}

Ethics approval was obtained from the Ethikkomission Charité.

\section{Patients}

In the period between April 2009 and March 2013 a total of 123 patients were recruited for this study (for detailed patient characteristics see Table 1). We collected and analyzed samples from 98 patients with SLE, 14 patients with DN and 11 patients with AAV.
We divided the SLE population into a group with active renal involvement $(n=19)$ and a group with nonactive renal involvement $(n=79)$. The systemic lupus erythematosus Disease activity index (SLEDAI) was calculated for all patients. Active renal involvement was defined by high overall disease activity (SLEDAI $\geq 10$ ) and a current kidney biopsy (not older than 4 weeks) showing $\mathrm{LN}(\mathrm{n}=14)$. In the absence of a biopsy, active renal involvement was defined by high disease activity (SLEDAI $\geq 10)$ and at least two elements of the renal SLEDAI $(n=5)$. All examined biopsies showed class IV $(n=10)$ or class IV $+V(n=3)$ except one case of pauci immune glomerulonephritis (see Additional file 1: Table S1).

Clinical follow-up data 6 months after the inclusion in the study were retrospectively retrieved from the medical files and were available for patients with initially active LN and 20 SLE patients who initially had no disease or had mildly active disease (SLEDAI <10). If 6-month follow-up data were not available, follow-up data collected 5 or 7 months after the urine analysis were accepted as a substitute. Remission was defined as a reduction in proteinuria by at least $50 \%$ and improvement or stabilization of creatinine 6 months after initiation of therapy for proliferative LN; refractory disease was defined as failure to achieve remission. In our cohort of eight patients with active LN, five achieved remission. Development of a new renal flare was defined as an increase in proteinuria or worsening creatinine attributed to SLE activity by the treating physician. In our cohort two patients developed a new renal flare.

Datasets of 71 SLE patients were included in the analysis of urinary cells, and the $\mathrm{T}$ cell subset analysis was performed in 53 SLE patients. Due to limited urinary cell numbers not all tests could be performed in every patient. No patients were excluded after analysis.

Our AAV cohort consisted of eight cases of granulomatosis with polyangiitis (formerly known as Wegener's granulomatosis) and three patients with perinuclear ANCA-associated disease. All patients had AAV-related

Table 1 Patient characteristics

\begin{tabular}{|c|c|c|c|c|}
\hline & SLE, active renal disease & SLE, non-active renal disease & $\begin{array}{l}\text { Diabetic } \\
\text { nepharopathy }\end{array}$ & $\begin{array}{l}\text { ANCA associated } \\
\text { vasculitis }\end{array}$ \\
\hline Number & 19 & 79 & 74 & 11 \\
\hline Female/male, number & $17 / 2$ & $71 / 8$ & $6 / 8$ & $4 / 7$ \\
\hline Age, years & 31 (19 to 60$)$ & 44 (21 to 72$)$ & 58 (27 to 93$)$ & 63 (38 to 78) \\
\hline SLEDAI & 14 (11 to 23$)$ & $2(0$ to 10$)$ & na & na \\
\hline BVAS & na & na & na & 5 (0 to 16$)$ \\
\hline Immunosuppresive treatment & $\begin{array}{l}19 \times \text { Pred } 7 \times \text { Cyc, } 1 \times \text { Aza } \\
13 \times \mathrm{HCQ}, 2 \times M M F\end{array}$ & $\begin{array}{l}62 \times \text { Pred, } 20 \times \text { Aza, } 37 \times \text { HcQ, } \\
15 \times \text { MMF, } 3 \times \text { MTX, } 3 \times \text { Belim, } \\
1 \times \text { Flebo }\end{array}$ & $1 \times \operatorname{Rtx}$ & $9 \times$ Pred, $1 \times$ Cyc, $6 \times$ Aza, $2 \times$ Rtx \\
\hline Prednisolone dose, mg, median (IQR) & 40 (30 to 50$)$ & $5.0(5.0$ to 7.5$)$ & - & $5.0(2.5$ to 5.0$)$ \\
\hline
\end{tabular}

Values are mean (range) unless stated otherwise. Aza, azathioprine; Belim, belimumab; BVAS, Birmingham Vasculitis Activity Score; Cyc, pulse cyclophosphamide; $\mathrm{HCQ}$, hydroxychloroquine; Flebo, flebogamma; MMF, mycophenolate mofetil; MTX, methotrexate; na, not applicable; Pred, prednisolone; Rtx, rituximab; SLE, systemic lupus erythematosus; SLEDAI, systemic lupus erythematosus disease activity index. 
renal involvement. AAV disease activity was measured by the Birmingham vasculitis activity score (BVAS).

Samples were collected from patients of the Department of Rheumatology and Clinical Immunology and Nephrology, Charité University Hospital, Berlin, Germany. The ethics committee of Charité University Hospital (Charité EA1/ 034/10) approved the study. Informed consent was obtained from all patients before participation.

\section{Sample preparation and flow cytometry}

Urine samples were collected and immediately centrifuged. Pellets were washed with PBS/ BSA. The median sample size was $100 \mathrm{ml}$ urine. To assure a high percentage of living urinary cells during measurements, only fresh urine was analyzed, while samples older than $6 \mathrm{~h}$ were discarded. Peripheral blood mononuclear cells were acquired by incubating fresh blood samples for 20 minutes at $4^{\circ} \mathrm{C}$ with erythrocyte lysis buffer and washing with PBS/BSA. Cells were stained with CD3-PE, CD4-PE, CD4-FITC, CD8-PE/ Cy7, CD14-PerCP/Cy5.5, CD25-FITC, CD28-PerCP/Cy5.5, CD40L-FITC, CD45RO-APC, CD127-APC, CCR7-FITC and FoxP3-Alexa488 (all Biolegend, San Diego, CA, USA), CD3-APC/Vio770 and CD25-APC (both Miltenyi Biotec $\mathrm{GmbH}$, Bergisch Gladbach, Germany), CD4-Cy5, CD8FITC, CD14-FITC and CD19-Cy5 (all DRFZ) and CD127eFluor (eBioscience, San Diego, CA, USA).

To block unspecific binding, cells were stained in PBS/ BSA containing 10\% human IgG (Flebogamma; Grifols, Langen, Germany); to exclude dead cells, either propidium iodide (Sigma-Aldrich, Steinheim, Germany) or diamidino phenylindole (Sigma-Aldrich, Steinheim, Germany) was added immediately before flow cytometry. In case of fixation, exclusion of dead cells was achieved by a Dead Cell discrimination kit (Miltenyi Biotec $\mathrm{GmbH}$, Bergisch Gladbach, Germany). To calculate cell numbers, defined sample sizes were acquired and the number of cells normalized as cells/dl of the initial urine sample. The samples were measured using a Calibur flow cytometer (BD Pharmingen, Heidelberg, Germany) and a MACS Quant Analyzer (Miltenyi Biotec GmbH, Bergisch Gladbach, Germany). Datasets were analyzed using Flowjo Software (Tree Star, Ashland, OR, USA).

\section{Routine laboratory values}

Routine laboratory values for serum creatinine and proteinuria were additionally gathered. Creatinine was measured by the Jaffe reaction, 24-h urinary protein excretion using a turbimetric assay.

\section{Statistical analysis}

Medians, Mann-Whitney tests, Wilcoxon matched pairs tests, Spearman correlation, and receiver operator characteristic (ROC) curves were calculated using GraphPad Prism 5 (GraphPad Software, San Diego, CA, USA).

\section{Results}

Patients with active LN had elevated amounts of urinary cells

Urine samples from patients with high disease activity (SLEDAI $\geq 10)$ and recent biopsy-proven $\mathrm{LN}(\mathrm{n}=14)$ or high renal disease activity (SLEDAI $\geq 10$ and renal SLE$\mathrm{DAI} \geq 8, \mathrm{n}=5$ ) had high numbers of both CD4+ (median 1,415 cells/dl urine) and CD8+ T cells (median 1,911 cells/dl urine). Even higher numbers of urinary CD14+ macrophages were observed with a median of 33,808 cells/dl urine $(n=19)$. In comparison, CD19+ B cells (median 231cells/dl urine) were only moderately increased in the urine of active patients $(n=10)$ (Figure 1A and $\mathrm{B})$.

In SLE patients without active renal involvement only low numbers of $\mathrm{T}$ cells were detected (median 29 CD4+ and $25 \mathrm{CD} 8+\mathrm{T}$ cells/dl urine, $\mathrm{n}=55$ ). With a median of 29 cells/dl urine, CD19+ B cell counts were similar to $\mathrm{T}$ cell counts in these patients $(n=29)$. However we frequently observed considerable amounts of CD14+ macrophages in the urine of these patients, (median 264 cells/dl urine, $\mathrm{n}=29$ ) (Figure $1 \mathrm{C}$ ). Differences in urinary cell counts between patients with active and non-active SLE were highly significant for CD3 + CD4+, CD3 + CD8+ and CD14+ cells $(P<0.0001)$ and to a lesser degree also for CD19+ cells $(P=0.0137)$. The disease activity (SLEDAI) correlated with the urinary cell counts of CD3 + CD4+ $(r=0.7363, P<0.0001), \mathrm{CD} 3+\mathrm{CD} 8+(r=0.7641$, $P<0.0001), \mathrm{CD} 14+(r=0.5715, P<0.0001)$ and CD19+ cells ( $r=0.4636, P<0.0030)$.

In DN patients, a median of $262 \mathrm{CD} 4+$ and $82 \mathrm{CD} 8+$ urinary $\mathrm{T}$ cells were detected, which was slightly higher than CD19+ B cell counts (median 69/dl) and considerably lower than CD14+ macrophage numbers (median $3,770 / \mathrm{dl}$ ) (Figure 1D). Patients with AAV had variable urinary lymphocyte counts, while urinary macrophages were detectable in all samples (Figure 1E). Cell counts did not correlate with the BVAS (data not shown).

\section{CD4/CD8-ratio was shifted towards CD8 in the urine of SLE patients and varied between different renal diseases} In order to determine the relations between urinary CD4+ and CD8+ cell counts in different renal diseases, a CD4/CD8 ratio was calculated for urine samples of patients with at least $100 \mathrm{CD} 3+$ cells/dl urine. The examined cohorts consisted of 38 SLE patients, 11 patients with DN and 7 patients with AAV (Figure 2).

Whereas SLE patients typically had slightly higher urinary CD8+ than CD4+ T cell counts (median 0.696 urinary $\mathrm{CD} 4 / \mathrm{CD} 8$-ratio) regardless of disease activity or known renal involvement, patients with severe DN showed reciprocal proportions in most cases (median 2.306 urinary CD4/CD8-ratio). The difference between urinary CD4/CD8-ratios in patients with SLE and DN 
A
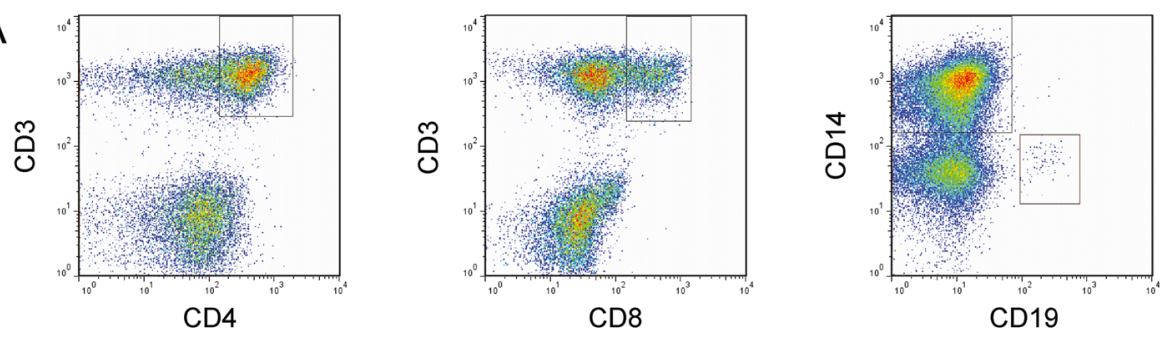

B

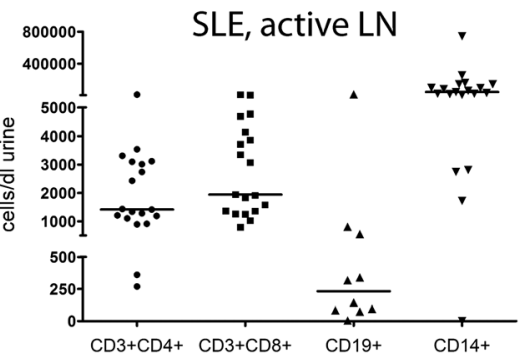

C

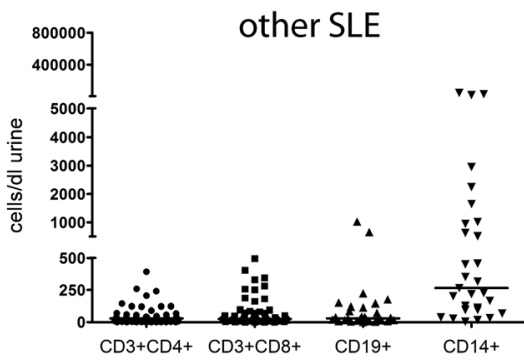

D

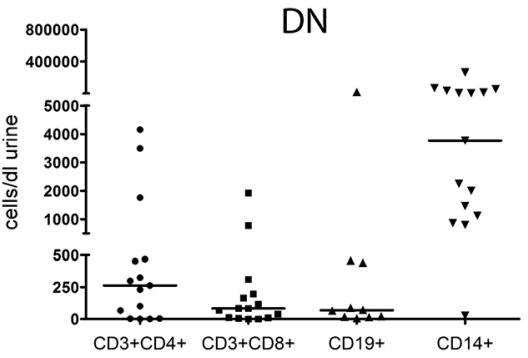

E

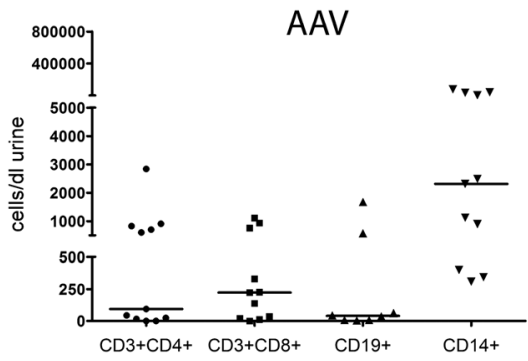

Figure 1 Urinary cells in systemic lupus erythematosus (SLE) patients and in patients with different nephropathies. (A) Examplary dot-plots of the flowcytometric analysis of urinary T cells, B cells and monocytes in a patient with acute proliferative lupus nephritis (LN). (B-E) Urinary cells in patients with acute proliferative LN (B), other SLE patients (C), patients with diabetic nephropathy (DN) (D) and patients with ANCA-associated vasculitis (AAV) (E)

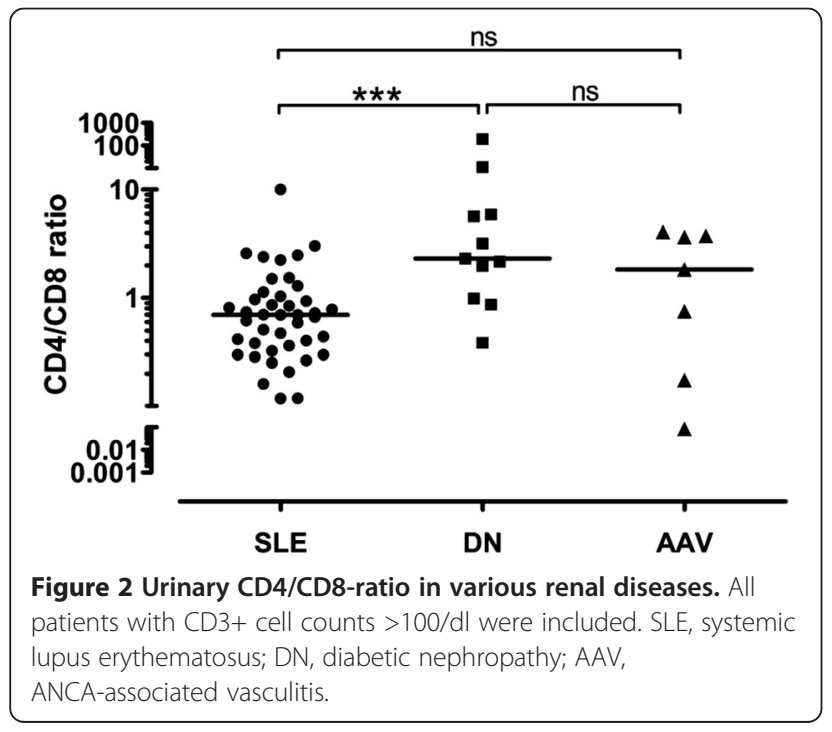

was highly significant $(P=0.0006)$. Patients with AAV had a high range of CD4/CD8-ratios (median 1.826 CD4/CD8-ratio, ranging from 0.085 to 4.067), which did not correlate with the BVAS. Comparing the ratios of AAV patients with SLE $(P=0.2591)$ or DN patients $(P=$ 0.2391 ) did not lead to any significant results. Other formed ratios, CD3/CD14 and CD3/CD19, did not yield any significant differences between diseases, either (data not shown).

\section{Subtyping of urinary CD4+ T cells in LN}

To evaluate the phenotype of urinary $\mathrm{CD} 4+\mathrm{T}$ cells, urine and blood samples of 10 SLE patients with acute proliferative $\mathrm{LN}$ were analyzed for various $\mathrm{T}$ cell surface markers as well as intracellular markers ki-67 and FoxP3 (Figure 3). All patients had either recently undergone kidney biopsy $(n=9)$ or had high overall disease acitivity and renal disease activity (SLEDAI $\geq 10$ and renal SLEDAI $\geq 8, n=1$ ). Total $\mathrm{T}$ cell subtype counts were also measured in additional urine samples from 43 SLE patients without acute renal involvement. 


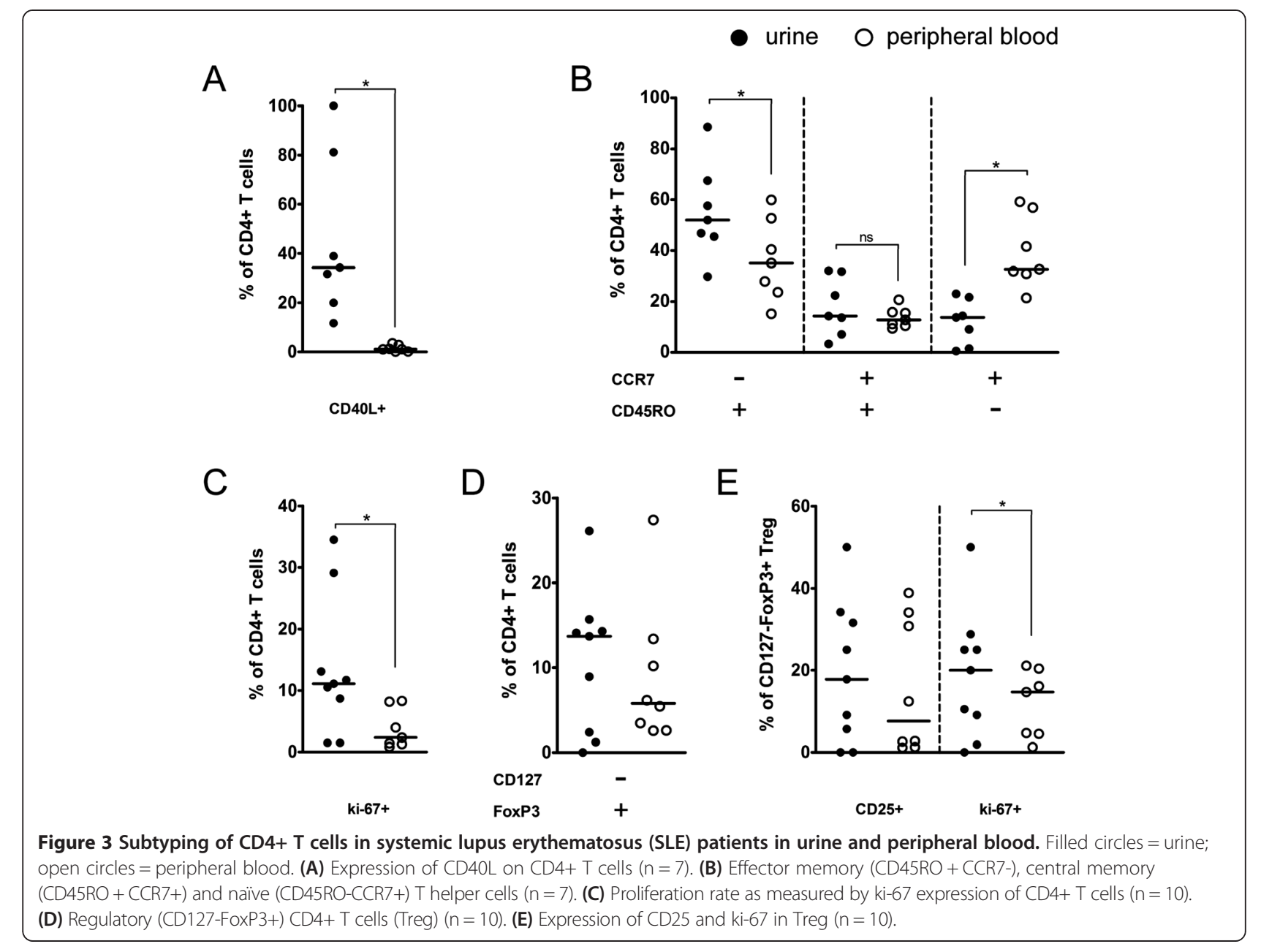

Urinary CD4+ $\mathrm{T}$ cells had a significantly higher expression of activation marker CD40L in comparison to the peripheral blood $(P=0.0156)$. The phenotype of urinary cells was shifted towards a higher percentage of effector memory type $\mathrm{T}$ helper cells (CD45RO + CCR7-) $(P=0.0156)$, while less naïve $\mathrm{T}$ cells $(\mathrm{CD} 45 \mathrm{RO}-\mathrm{CCR} 7+)$ were found in the urine $(P=0.0156)$ when compared to peripheral blood. No differences between urine and blood $\mathrm{CD} 4+\mathrm{T}$ cells were detected for the frequency of central memory $(\mathrm{CD} 45 \mathrm{RO}+\mathrm{CCR} 7+)$, regulatory CD127-FoxP3+ $\mathrm{T}$ cells (Treg) and CD25+ Treg. The proliferation rate as measured by ki-67 of both overall CD4+ T cells and Treg was significantly increased in the urine $(P=0.0156$ and 0.0313 , respectively). Analysis of surface marker CD28 did not yield any significant differences between urine and blood for either CD4+ or CD8+ T cells (data not shown).

Correlation between the urinary cell counts of all measured patient samples with the SLEDAI was not significant for the urinary cell counts of CD40L+, naïve, effector memory or central memory T cells. Treg, however, correlated with the disease activity $(\mathrm{n}=22, r=$ 0.5551, $P<0.0073)$.

\section{Diagnostic value of urinary cells}

ROC curves were used to calculate and compare sensitivity and specificity of different urinary cell types and $\mathrm{T}$ cell subsets for identifying acute proliferative LN among SLE patients (Figure 4). For comparison, additional ROC calculations for approved clinical markers proteinuria and serum creatinine were made. The control group comprised other SLE patients with no active renal disease or no renal disease at all.

Of all tested markers (Table 2), CD8+ T cells yielded the highest diagnostic value with an area under the ROC curve (AUC) of 1.000. CD4+ T cells performed similarly well (AUC $=0.9969)$ and better than the established laboratory markers proteinuria $(\mathrm{AUC}=0.9201$ ) or serum creatinine (AUC $=0.6031$ ). Urinary $C D 19+B$ cells and CD14+ macrophages failed to reach these high standards, while subtyping of CD4+ T cells did not yield any improvement of the marker.

To evaluate whether a certain urinary immune cell composition predicts a clinical course, $6(+/-1)$-month clinical follow-up data were retrieved from patients files. Clinical follow up was available for eight patients with 

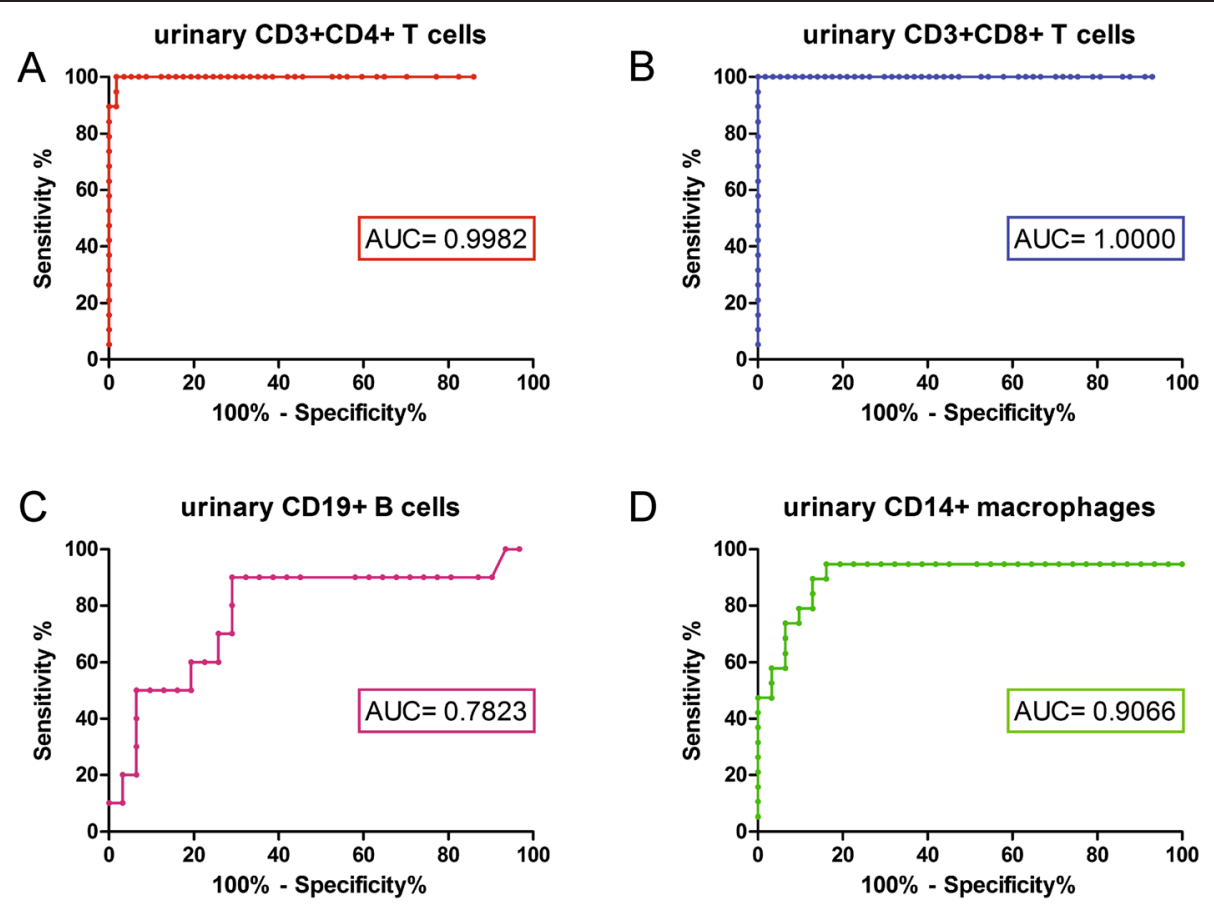

Figure 4 Receiver operater characteristic (ROC) curve for diagnosing proliferative lupus nephritis (LN) among systemic lupus erythematosus (SLE) patients with various urinary cell types. (A) CD3 + CD4+ T cells; (B) CD3 + CD8+ T cells; (C) CD19+ B cells; (D) CD14+ macrophages. AUC, area under the curve.

initially active $\mathrm{LN}$, five of whom achieved remission and three of whom were refractory. No significant differences in the initial urinary CD4+ T cell, CD8+ T cell, CD19+ B cell or CD14+ macrophage counts were observed. There was also no difference between refractory LN or response to therapy for regulatory CD4+ T cell or ki67 + CD4+ T cell counts. Among the 20 patients with non-active/mildly active SLE with 6-month clinical follow up, 18 patients showed no disease activity while one suffered severe, biopsy-proven LN class IV LN and another patient with known class V LN developed drastically increased proteinuria. Both patients had moderately elevated urinary $\mathrm{T}$ cell counts 7 months prior to the new renal flares (median 316 CD4+ T cells/dl and $268 \mathrm{CD} 8+\mathrm{T}$ cells/dl), while all other patients had only marginally detectable urinary $\mathrm{T}$ cells (median $13 \mathrm{CD} 4+\mathrm{T}$ cells/dl and 24 CD8+ T cells/dl).

Table 2 ROC for diagnosing proliferative LN among SLE patients with various urinary cell types as markers

\begin{tabular}{|c|c|c|c|c|c|c|}
\hline Examined marker & $\begin{array}{l}\text { Patients } \\
(\mathrm{n}=)\end{array}$ & $\begin{array}{l}\text { Controls } \\
(n=)\end{array}$ & Area under the ROC curve & Cutoff & $\begin{array}{l}\text { Sensitivity } \\
(\%)\end{array}$ & $\begin{array}{l}\text { Specificity } \\
(\%)\end{array}$ \\
\hline $\mathrm{uCD} 3+\mathrm{CD} 8+$ & 17 & 55 & 1.0000 & $>650$ cells/dl & 100 & 100 \\
\hline $\mathrm{uCD} 3+\mathrm{CD} 4+$ & 19 & 55 & 0.9982 & $>270$ cells/dl & 100 & 98.25 \\
\hline CCR7-CD45RO+ & 6 & 34 & 0.9832 & $>300$ cells/dl & 100 & 94.12 \\
\hline $\mathrm{CCR7}+\mathrm{CD} 45 \mathrm{RO}+$ & 6 & 34 & 0.8172 & $>35$ cells/dl & 85.71 & 79.41 \\
\hline CCR7 + CD45RO- & 6 & 34 & 0.7941 & $>45$ cells/dl & 100 & 52.94 \\
\hline CD40I+ & 6 & 34 & 0.9706 & $>100$ cells/dl & 100 & 70.59 \\
\hline CD127-FoxP3+ & 7 & 13 & 0.9017 & $>5$ cells/dl & 77.78 & 84.44 \\
\hline Proteinuria & 16 & 45 & 0.9201 & $>620 \mathrm{mg} / \mathrm{d}$ & 93.75 & 83.87 \\
\hline uCD14+ & 17 & 31 & 0.9066 & $>1700$ cells/dl & 94.74 & 83.87 \\
\hline uCD19+ & 10 & 31 & 0.7823 & $>75$ cells/dl & 90 & 70.97 \\
\hline Creatinine & 19 & 55 & 0.6031 & $>1.1 \mathrm{mg} / \mathrm{dl}$ & 47.37 & 79.17 \\
\hline
\end{tabular}

Arranged according to area under the receiver operator characteristic (ROC) curve; cutoff determined by Youden's index. 


\section{Discussion}

This investigation provides information on the occurrence of several inflammatory urinary cell types in SLE and their relevance as a biomarker for proliferative LN. $\mathrm{T}$ lymphocytes were confirmed as the most reliable urinary biomarker for active LN, while urinary macrophages and $\mathrm{B}$ cells failed to emerge as diagnostic biomarkers. These urinary cells are not unique for LN but are also present in other inflammatory diseases like DN and AAV. However, the balance of urinary $\mathrm{T}$ cells seems to be shifted towards CD8+ T cells in LN.

Relevance of the local inflammatory infiltrating cells in the pathogenesis of LN is well-established [20]. Histology studies have reported that in LN the interstitial infiltration consists mainly of $\mathrm{T}$ cells and to a lesser extent of macrophages, B cells and plasmablasts/-cells [21]. Several authors describe a predominance of CD4+ T cells $[17,21]$, while others report a majority of CD8 $+\mathrm{T}$ cells $[22,23]$. Solving this contradiction Winchester described different patterns of infiltration in LN, some predominated by $\mathrm{CD} 4+$ others by $\mathrm{CD} 8+\mathrm{T}$ cells and also mixed CD4/ CD8 infiltrations [24]. At present, the origin of immune cells in the urine is unknown and the relative contribution of periglomerular and peritubular infiltrates and large interstitial aggregates contribution to the urinary leukocytes is unclear. Nevertheless the cells in the urine seem to resemble the intra-renal cellular distribution, although macrophages outnumber other cell types in the urine.

Surprisingly high urinary macrophage counts were observed in several patients without clinical disease activity or known active nephritis. The significance of these cells is presently unknown, nevertheless it is tempting to speculate whether they reflect subclinical inflammation. Or, on the contrary, these macrophages may also exert anti-inflammatory effects, protecting the kidney against renal flares.

Based on our findings, a high percentage of urinary CD4+ T cells in SLE patients seemed to be of the effector memory phenotype. This matches the results of a recent report on LN [12] and similar observations that were made in acute AAV [19]. The higher activation $(\mathrm{CD} 40 \mathrm{~L}+)$ and proliferation (ki67+) of urinary CD4+ T cells stated in our results is plausible, given the inflammatory context and overall higher CD40L expression on $\mathrm{T}$ cells in proliferative LN [25]. In addition, a variable amount of Foxp3 + CD127- Treg was found in the urine (Figure 3) besides effector $\mathrm{CD} 4+\mathrm{T}$ cells, which correlated with disease activity.

Urinary $\mathrm{T}$ cells have already been reported as an excellent biomarker to diagnose proliferative LN among SLE patients $[10,11]$. In the present study the urinary CD8+ $\mathrm{T}$ cell count was slightly superior to $\mathrm{CD} 4+\mathrm{T}$ cells as a biomarker for active LN. Notably, both T cell types performed better in diagnosing $\mathrm{LN}$ than proteinuria or creatinine. Further sub phenotyping of urinary $\mathrm{CD} 4+\mathrm{T}$ cells as performed in this study may be helpful for a better understanding of LN pathogenesis but does not improve $\mathrm{T}$ cells as a biomarker. Other urinary cell types did not hold up to the high standard of urinary $\mathrm{T}$ cells: while urinary B cell counts are in most cases too low in active LN patients to sufficiently distinguish them from other SLE patients, the high urinary macrophage count in some patients with non-active SLE leads to a large number of false positive results.

In a limited cohort we were able to probe whether certain immune cells in the urine may be predictive of a certain clinical course. Intriguingly, mildly elevated $\mathrm{T}$ cells seemed to potentially predict renal flares, which need to be analyzed in the future. Obviously our sample size and study design was inappropriate to make a definite conclusion but these observations are hypothesis-generating.

The occurrence of urinary cells in other diseases has already been reported previously [10,19,26,27]. Here we compared the urinary cell composition of LN with other nephropathies associated with an inflammatory infiltration: Concerning urinary cells, AAV seems to be a disease similar to LN. T cell counts correlating with disease activity have been reported for both renal manifestations $[10,13,19]$ and no difference in the cellular composition in the urine was observed in our study. $\mathrm{DN}$ is increasingly considered an inflammatory disease [28]. In a recent study, Moon et al. indicated that intrarenal infiltration and activation of $\mathrm{T}$ cells in the interstitium is the main mechanism of kidney injury and showed a predominant CD4+ $\mathrm{T}$ cell renal infiltration in mice with induced diabetes [29]. In line with these reports we identified various amounts of urinary leucocytes in patients with DN. The assessment of urinary cells in DN patients revealed that overall cell counts are lower than in $\mathrm{LN}$ patients but proportions of $\mathrm{T}$ cells, B cells and macrophages are comparable. The ratio of urinary $\mathrm{CD} 4+$ and $\mathrm{CD} 8+\mathrm{T}$ cells marks the only exception. Considering the decreased CD4/CD8-ratio in the peripheral blood of SLE patients [30], this finding is not surprising. However, these differences in the composition of urinary $\mathrm{T}$ cells might be helpful in the otherwise difficult urinary distinction between LN and other diseases: The CD4/CD8-ratio is a quotient usually used in the monitoring of $\mathrm{T}$ lymphocytes in HIV-positive patients or as a marker for diagnosing sarcoidosis via bronchial lavage $[31,32]$. However, when applied for urinary T cells, the ratio differs significantly between SLE and DN patients and reflects the differences in the respective intra-renal infiltrates. Other ratios, like the urinary $\mathrm{CD} 14 / \mathrm{CD} 3$ ratio, which has been reported as helpful in differential diagnosis of glomerular diseases [26,27] did not yield any significant results. However, our data for both DN and AAV were restricted by low patient numbers and need to be confirmed by future studies. 


\section{Conclusion}

Our data present a comprehensive view of urinary cells in SLE. Urinary T cells, especially CD8+ T cells, maintain their leading role as cellular urinary biomarkers for proliferative LN, although both $\mathrm{B}$ cells and macrophages can be detected in the urine. In the near future, this non-invasive monitoring of urinary compounds might become a useful tool to facilitate clinical decisions on kidney biopsies and the treatment of LN.

\section{Data sharing statement}

Data not shown in the manuscript include correlation analysis of several urinary cell types with the respective disease activity scores, comparisons of urinary CD3/CD14 and CD3/CD19 ratios between SLE, DN and AAV and expression of CD28 on CD4+ and CD8+ T cells. These datasets are available via email to the corresponding author.

\section{Additional file}

Additional file 1: Table S1. Detailed characteristics of acute lupus nephritis patients. Every row represents one patient. IV $(+V)$, Lupus nephritis class IV (+ V); G, global involvement; A, active lesions; C, chronic lesions; * pauci immune glomerulonephritis. Aza, azathioprine; Cyc, pulse cyclophosphamide; HCQ, hydroxychloroquine; MMF, mycophenolate mofetil; Pred, prednisolone.

\begin{abstract}
Abbreviations
AAV: anti-neutrophil cytoplasmatic antibody associated vasculitis; ANCA: anti-neutrophil cytoplasmatic antibody; APC: allophycocyanin, fluorescent dye; AUC: area under the curve; Aza: azathioprine; Belim: belimumab; BSA: bovine serum albumin; BVAS: Birmingham vasculitis activity score; CCR: CC-motif chemokine receptor; CD: cluster of differentiation; Cy5, Cy7: cyanine fluorescent dyes; Cyc: cyclophosphamide; DN: diabetic nephropathy; DRFZ: German Rheumatism Research Center; FITC: fluorescein isothiocyanate, fluorescent dye; Flebo: flebogamma; HCQ: hydroxychloroquine; LN: lupus nephritis; MMF: mycophenolate mofetil; MTX: methotrexate; na: not applicable; PBS: phophate-buffered saline; PE: phycoerythrin, fluorescent dye; PerCP: peridinin-chlorophyll proteins, fluorescent dye; Pred: prednisolone; ROC: receiver-operator characteristic; Rtx: rituximab; SLE: systemic lupus erythematosus; SLEDAl: systemic lupus erythematosus disease activity index.
\end{abstract}

\section{Competing interests}

The authors declare that they have no competing interests.

\section{Authors' contributions}

KK and JK had full access to all of the data in the study and take responsibility for the integrity of the data and the accuracy of the data analysis. Study design: KK, JK, PE, GR. Acquisition of data: KK, JK, ASG, PE. Analysis and interpretation of data: KK, JK, ASG, JYH, RB, DD, GRB, PE, GR. Manuscript preparation: KK, JK, ASG, JYH, RB, DD, GRB, PE, GR. All authors read and approved the manuscript.

\section{Acknowledgements}

We thank all patients for sample donations. This work was supported by the Deutsche Forschungsgemeinschaft (SFB 650) and grants from the University Hospital Charité Berlin and Stiftung Charité

Received: 24 October 2014 Accepted: 17 March 2015

Published online: 03 April 2015

\section{References}

1. Borchers AT, Leibushor N, Naguwa SM, Cheema GS, Shoenfeld Y, Gershwin ME. Lupus nephritis: a critical review. Autoimmun Rev. 2012;12:174-94.
2. Ward MM. Changes in the incidence of endstage renal disease due to lupus nephritis in the United States, 1996-2004. J Rheumatol. 2009;36:63-7.

3. Alarcon GS. Infections in systemic connective tissue diseases: systemic lupus erythematosus, scleroderma, and polymyositis/dermatomyositis. Infect Dis Clin North Am. 2006;20:849-75.

4. Moore RA, Derry S. Systematic review and meta-analysis of randomised trials and cohort studies of mycophenolate mofetil in lupus nephritis. Arthritis Res Ther. 2006;8:R182.

5. Giannico G, Fogo AB. Lupus nephritis: is the kidney biopsy currently necessary in the management of lupus nephritis? Clin J Am Soc Nephrol. 2013;8:138-45

6. Preda A, Van Dijk LC, Van Oostaijen JA, Pattynama PMT. Complication rate and diagnostic yield of 515 consecutive ultrasound-guided biopsies of renal allografts and native kidneys using a 14-gauge Biopty gun. Eur Radiol. 2003;13:527-30

7. Rovin $\mathrm{BH}$, Zhang $\mathrm{X}$. Biomarkers for lupus nephritis: the quest continues. Clin J Am Soc Nephrol. 2009;4:1858-65.

8. Sciascia S, Ceberio L, Garcia-Fernandez C, Roccatello D, Karim Y, Cuadrado MJ. Systemic lupus erythematosus and infections: clinical importance of conventional and upcoming biomarkers. Autoimmun Rev. 2012;12:157-63.

9. Reyes-Thomas J, Blanco I, Putterman C. Urinary biomarkers in lupus nephritis. Clin Rev Allergy Immunol. 2011;40:138-50.

10. Enghard P, Rieder C, Kopetschke K, Klocke JR, Undeutsch R, Biesen R, et al. Urinary CD4 T cells identify SLE patients with proliferative lupus nephritis and can be used to monitor treatment response. Ann Rheum Dis. 2014;73:277-83.

11. Dolff $S$, Abdulahad WH, van Dijk AS, Marcory CRF, Limburg PC, et al. Urinary CD8+ T-cell counts discriminate between active and inactive lupus nephritis. Arthritis Res Ther. 2013;15:R36.

12. Dolff S, Abdulahad WH, van Dijk MC, Limburg PC, Kallenberg CG, Bijl M. Urinary $T$ cells in active lupus nephritis show an effector memory phenotype. Ann Rheum Dis. 2010;69:2034-41.

13. Enghard $P$, Humrich JY, Rudolph B, Rosenberger S, Biesen R, Kuhn A, et al. CXCR3 + CD4+ T cells are enriched in inflamed kidneys and urine and provide a new biomarker for acute nephritis flares in systemic lupus erythematosus patients. Arthritis Rheum. 2009;60:199-206.

14. Goulet JR, MacKenzie T, Levinton C, Hayslett JP, Ciampi A, Esdaile JM. The longterm prognosis of lupus nephritis: the impact of disease activity. J Rheumatol. 1993;20:59-65.

15. Yu F, Wu L, Tan Y, Li L, Wang C, Wang W, et al. Tubulointerstitial lesions of patients with lupus nephritis classified by the 2003 International Society of Nephrology and Renal Pathology Society system. Kidney Int. 2010;77:820-9.

16. Giannakakis K, Faraggiana T. Histopathology of lupus nephritis. Clin Rev Allergy Immunol. 2011;40:170-80.

17. Caligaris-Cappio F, Bergui L, Tesio L, Ziano R, Camussi G. HLA-Dr + T cells of the Leu 3 (helper) type infiltrate the kidneys of patients with systemic lupus erythematosus. Clin Exp Immunol. 1985;59:185-9.

18. Chan RW, Lai FM, Li EK, Tam LS, Chung KY, Chow KM, et al. Urinary mononuclear cell and disease activity of systemic lupus erythematosus. Lupus. 2006;15:262-7.

19. Abdulahad WH, Kallenberg CGM, Limburg PC, Stegeman CA. Urinary CD4+ effector memory $T$ cells reflect renal disease activity in antineutrophil cytoplasmic antibody-associated vasculitis. Arthritis Rheum. 2009;60:2830-8.

20. Bagavant H, Fu SM. Pathogenesis of kidney disease in systemic lupus erythematosus. Curr Opin Rheumatol. 2009;21:489-94.

21. Boucher A, Droz D, Adafer E, Noel LH. Characterization of mononuclear cell subsets in renal cellular interstitial infiltrates. Kidney Int. 1986;29:1043-9.

22. Couzi L, Merville P, Deminiere C, Moreau J, Combe C, Pellegrin J, et al. Predominance of CD8+ T lymphocytes among periglomerular infiltrating cells and link to the prognosis of class III and class IV lupus nephritis. Arthritis Rheum. 2007;56:2362-70.

23. D'Agati VD, Appel GB, Estes D, Knowles 2nd DM, Pirani CL. Monoclonal antibody identification of infiltrating mononuclear leukocytes in lupus nephritis. Kidney Int. 1986;30:573-81.

24. Winchester R, Wiesendanger $M$, Zhang H, Steshenko V, Peterson $K$, Geraldino-Pardilla $L$, et al. Immunologic characteristics of intrarenal T cells: trafficking of expanded CD8+ T cell beta-chain clonotypes in progressive lupus nephritis. Arthritis Rheum. 2012;64:1589-600.

25. Yellin MJ, D'Agati V, Parkinson G, Han AS, Szema A, Baum D, et al. Immunohistologic analysis of renal CD40 and CD40L expression in lupus nephritis and other glomerulonephritides. Arthritis Rheum. 1997;40:124-34. 
26. Hotta O, Yusa N, Kitamura H, Taguma Y. Urinary macrophages as activity markers of renal injury. Clin Chim Acta. 2000;297:123-33.

27. Hotta O, Yusa N, Ooyama M, Taguma Y. Urinary macrophage counts and ratio to T lymphocytes: possible use in differential diagnosis and management of glomerular disease. J Clin Lab Anal. 1996;10:205-8.

28. Hickey FB, Martin F. Diabetic kidney disease and immune modulation. Curr Opin Pharmacol. 2013;13:602-12.

29. Moon J, Jeong K, Lee T, Ihm C, Lim SJ, Lee S. Aberrant recruitment and activation of T cells in diabetic nephropathy. Am J Nephrol. 2012;35:164-74.

30. Maeda N, Sekigawa I, lida N, Matsumoto M, Hashimoto H, Hirose S.

Relationship between CD4+/CD8+ T cell ratio and T cell activation in systemic lupus erythematosus. Scand J Rheumatol. 1999;28:166-70.

31. Sainz T, Serrano-Villar S, Diaz L, Gonzalez Tome MI, Gurbindo MD, de Jose $\mathrm{Ml}$, et al. The CD4/CD8 ratio as a marker T-cell activation, senescence and activation/exhaustion in treated HIV-infected children and young adults. AIDS. 2013;27:1513-6.

32. Danila E, Norkuniene J, Jurgauskiene L, Malickaite R. Diagnostic role of BAL fluid CD4/CD8 ratio in different radiographic and clinical forms of pulmonary sarcoidosis. Clin Respir J. 2009;3:214-21.

\section{Submit your next manuscript to BioMed Central and take full advantage of:}

- Convenient online submission

- Thorough peer review

- No space constraints or color figure charges

- Immediate publication on acceptance

- Inclusion in PubMed, CAS, Scopus and Google Scholar

- Research which is freely available for redistribution 